\title{
The Analysis of Using ICT on Knowledge Management in Governmental Organizations in Iran (Case Study: Municipality of Mazandaran Province)
}

\author{
Neda Sharifi Asadi Malafe \\ Young Researchers and Elite Club, Sari Branch \\ Islamic Azad University, Sari, Iran \\ E-mail: neda.sharifii@yahoo.com \\ Fahime Baei (Corresponding author) \\ Young Researchers and Elite Club, Sari Branch \\ Islamic Azad University, Sari, Iran, \\ E-mail: baei.fahime@yahoo.com
}

Received: Feb. 26, 2017 Accepted: Oct. 6, $2017 \quad$ Published: October 6, 2017

doi:10.5296/jmr.v9i4.11957ＵRL: https://doi.org/10.5296/jmr.v9i4.11957

\begin{abstract}
This study was an attempt to investigate the relationship between information and communication technology (ICT) and its components and knowledge management in Iran municipality staff (Mazandaran Province). "Research Methodology" in this study was descriptive and correlational. To fulfill the purpose of this study, 152 staff were selected from among a total number of 250 population based on stratified sampling using Krejcie \& Morgan sampling table. "The data collection tools" consisted of two standard questionnaires, including ICT questionnaires (\%96 validity) and knowledge management questionnaire (95\% validity). "The data analysis method" was inferential statistics conducting by SPSS and LISREL software. "The results" showed that there was a significant relationship between ICT and knowledge management. Also, that there was a significant relationship between ICT components include: "automation", "processing", "storage", "informing" and "communication", and knowledge management. There was not a significant relationship
\end{abstract}




\section{Macrothink}

Journal of Management Research ISSN 1941-899X 2017, Vol. 9, No. 4

between ICT and knowledge management between men and women. Finally, the relationship between ICT and knowledge management model based on Fit Indices of, properly evaluated.

Keywords: ICT, knowledge management, staff 


\section{Introduction}

Today is the world of information and communication; a new era in the world of competition began with the third industrial revolution. "The Revolution" known as Third Millennium, was considered as the starting point for the development of economic and industrial criteria. Now ICT affected on various aspects of life such as political, social, economic, cultural, individuals and communities so that cannot be neglected. This technology enables people to access, process, store, retrieve and disseminate information efficiently. It also will help developing countries to compete effectively in the knowledge based global economy (Secretariat, 2005:83). Indeed, ICT refers to the interaction between the user and the world of information the bilateral relationship and in this process, the user plays a very active role in exchanging information (Mahdavi, 2010:32).

Organizations are faced with changes in the twenty-first century constantly. To be able to compete effectively in the competitive markets, the key point will be how organizations learn and produce new knowledge and consequently how they manage this knowledge. Due to early changes in management posts, the opportunity for managers to transfer knowledge and experience is not possible (Adli, 2005). In the past, many organizations used each employee's knowledge to improve his/her performance, while today the organizations are trying to use the knowledge of all employees in the organization, to achieve the goals of organization increasingly. This leads to the spread of new approach known as knowledge management (Rajabi \& Shahmohammadi, 2013:104). In fact, knowledge management is an attempt to reveal the hidden assets in the minds of the members, and transform these assets, so that all staff have access to it (Davenport \& Prusak, 1998; quoted by Ahmadi \& Mirzaee, 2014:32).

The key to the success and failure of knowledge management in organization is understanding and creating suitable conditions for the effective implementation of knowledge management and its processes (Robbins, 2008). Role of IT in knowledge management is an important issue for organizations that want to utilize technologies for the management of their intellectual capital(Azadi-Ahmadabadi \& Azadi-Ahmadabadi, 2009:56). Many factors have changed the opinion of organizations to knowledge and knowledge sharing, and cause organizational success in the implementation of knowledge management strategy. But one of the most important methods is very wide access to knowledge through new information and communication technologies. However, most scholars believe that technology and especially ICT is not a knowledge management. ICT is one of the major and broad channels to access knowledge (Wang \& Ahmed, 2003:57).

Knowledge management can be used as a strategy of independence, or low dependence from today's advanced technologies. Knowledge communities require something more than just physical space to enable group members to discuss about ideas with each other (Kheirandish \& et al., 2012:74). Technological approach to knowledge management is associated with higher initial costs, is inherently more measurable, and could do greater volume of transactions than employee knowledge (Bergeron, 2007: 161-162).

Information and communication technologies provide two major capabilities for knowledge management. First, they can create an expert system or decision support by imparting 
knowledge; Second, information technology help people with specific expertise to be informed of each other's activities, and provide the ability to communicate rapidly (Blvdgvd and Sales time, 2001:62). ICT influence on knowledge management through, gathering, storing and exchanging of knowledge, integration and consolidation of the various components of knowledge, removing barriers in communication, strengthening of creation way, transmission, storage and use of knowledge (Lee \& Choi, 2003:185).

ICT dimension is included automation, processing, storage, informing and communication (Damghanian \& et al., 2013). Several researches were carried out related to the subject of this study which some of them are mentioned below: Teresa \& Alvarez (2015), in a study entitled "Analysis of information and communication technologies in knowledge management" achieved that combine information and communication technologies has a positive effect on socialization, exposure, composition, the internalization of processes of knowledge management. Moreover, it became clear which technologies and knowledge management processes are useful. Rampay \& Sampvng (2015), in a study entitled "The development model of knowledge management to strengthen information and communication technology" achieved that the conclusion that many of CLS of ICT small, medium and large, have had problems and obstacles in the field of facility management and services. In addition, many small centers had no long-term planning activities, and preserved and collected the small local study. Damghanian \& et al. (2013), in a study entitled "The impact of information technology on knowledge management mediated by empowerment" achieved that IT has a significant and positive relationship through the "empowerment" with "knowledge management" directly and indirectly. Sobhani \& et al.(2013), In a study entitled "The relationship between information technology and knowledge management" achieved that there is a significant and positive relation between the components of information technology and knowledge management. The regression results indicate that IT components of IT are significant predictor for knowledge management. Yang \& et al. (2012), in a study entitled "The Impact of Information Technology on project success through knowledge management practice" achieved that the application of Information Technology positively associated with levels of knowledge management projects. In addition, the project results can be achieved with higher levels of knowledge management. The findings also showed that knowledge management practice approved the mediation effect of IT on the performance of the project in terms of program success, cost savings as well as quality and safety performance. In addition, these results suggest that the relationship between the team and the size of the team have a moderating effect on the relationship between knowledge management and project success. Kheirandish \& et al. (2012), in a study entitled "The role of technological factors in the success of knowledge management in organizations" achieved that there is a significant relation between knowledge management and technological component. As well as there is a significant difference between the current situation of components and the desirable situation of components and a different priority of component is in influencing knowledge management. Damghanian \& et al.(2011), in a study entitled "Comparison of knowledge management and information technology among women and men" achieved that there is a significant difference between men and women in terms of knowledge management. While there is no significant difference between these two groups in terms of IT. The mean score of 


\section{Ml Macrothink}

Journal of Management Research

ISSN 1941-899X

2017, Vol. 9, No. 4

knowledge management among women is higher than that of men. Niels \& Johnson (2010), in a study entitled "Information management as an enabler of knowledge management maturity" achieved that IT can be effective in strengthening knowledge management. Tseng (2008), in a study entitled "The Impact of Information Technology on knowledge management systems" found that there is a significant relationship between IT and knowledge management. In this study the ICT pattern of Damghanian \& et al. (2013) and knowledge management pattern of Nonaka and Takeuchi (1995) was performed. As a result the analytical model based on Figure 1 presented below.

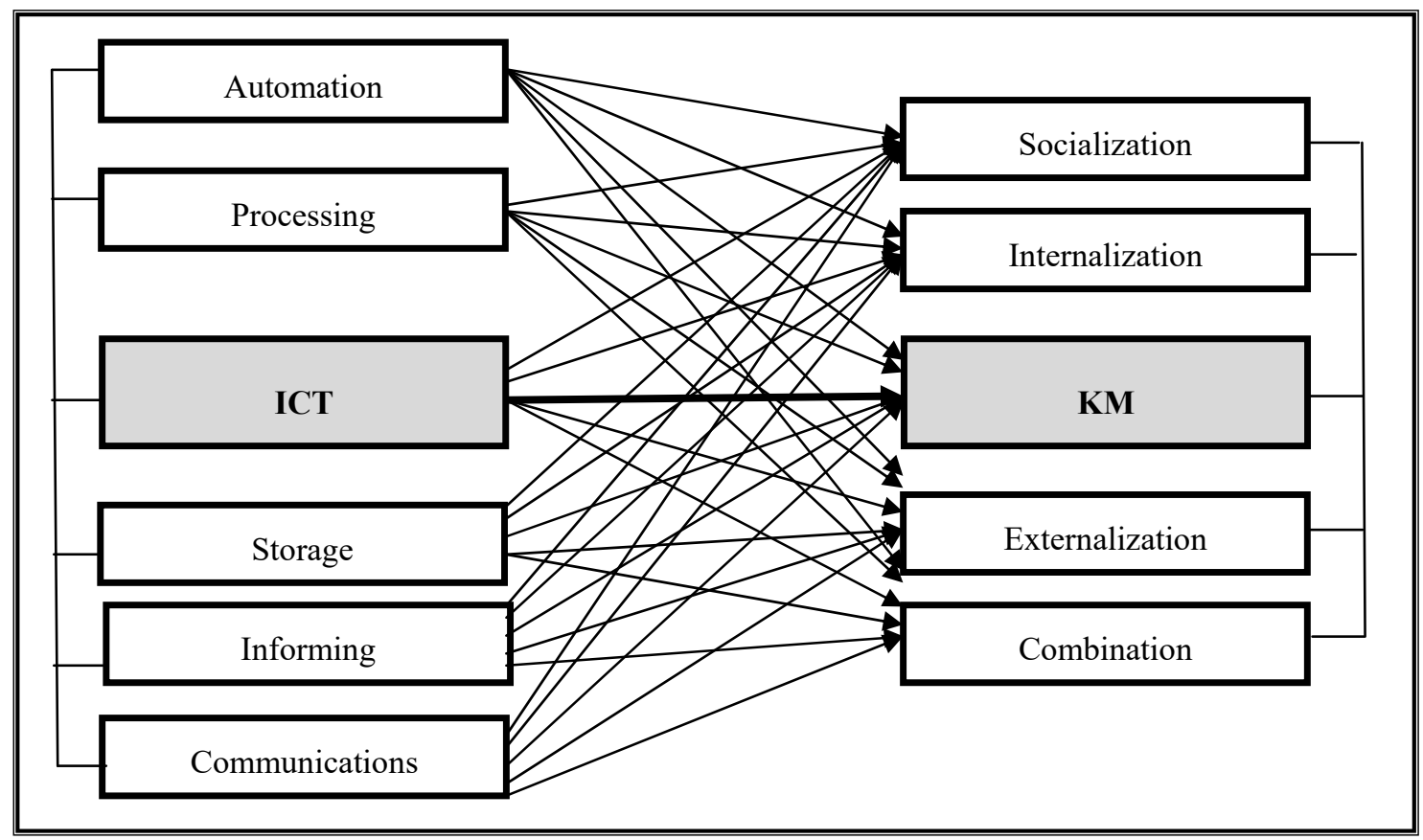

Figure 1. Analytical model of the relationship between ICT and knowledge management (self-made)

Considering that studies show that there is direct relationship between ICT and knowledge management, one of the goals of managers in the organization is promotion of investment in appropriate technologies for knowledge management projects. This research seeks to answer this main question: "Is there a relationship between ICT and knowledge management in Sari municipality staff? In line with the preceding question, the following hypotheses were stated:

- $\quad \mathbf{H}_{1}$ : There is a significant relation between ICTs and knowledge management.

- $\quad \mathbf{H}_{2}$ : There is a significant relation between ICT and its components and component of knowledge management.

- $\quad \mathbf{H}_{3}$ : There is a significant difference between ICT and knowledge management separately between men and women. 


\section{Methodology}

Methodology in this study was descriptive and correlational. 152 staff (including 36 women and 116 men) were selected from among a total number of 250 population based on stratified sampling using Morgan sampling table. The data collection tools consisted of two standard questionnaires based on Likert scale (1. Strongly Agree; 2. Agree; 3.Undecided; 4. Disagree; 5. Strongly Disagree). By using them the relationship between identified variables of research was examined: ICT questionnaires of Damghanian et al. which had 28 questions with the validity of $96 \%$, was designed to measure components: automation, processing, storage, informing, communications \& knowledge management questionnaire of Nonaka and Takeuchi which had 26 questions with the validity of $95 \%$ was used to measure features: socialization, integration, Externalization, Combination. Worth mentioning congruent validity of the questionnaires was examined by Cronbach's alpha (CA) test. The data analysis method was inferential statistics (Pearson correlation and correlation comparison of two independent groups Z-Fisher test) conducting by SPSS (model under test $t$ ) and in this research, we used structural equation modeling (it shows: 1.The relationship of latent variables. 2. The relationship of observed variables and latent variables) for measuring the latent variables by two or more observed variables and found that, observed variables how much are under influence of latent variables and errors. For reaching to these aims, we used Spss22 and Lisrel 8.5 software.

\section{Results}

- The first hypothesis (the main): There is a significant relation between ICT and knowledge management.

$\mathrm{H}_{0}: \mathbf{r}=\mathbf{0}$

$\mathrm{H}_{1}: \mathbf{r} \neq \mathbf{0}$

Table 1. Relationship between ICT and KM

\begin{tabular}{|c|c|c|}
\hline $\begin{array}{l}\text { Criterion variable } \\
\text { Predictive variable }\end{array}$ & & $\mathbf{K M}$ \\
\hline \multirow{4}{*}{ ICT } & \multirow{4}{*}{ 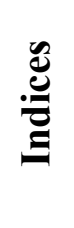 } & $\mathrm{r}=0.51^{* *}$ \\
\hline & & $\mathrm{R}^{2}=0.26$ \\
\hline & & Sig $=0.000$ \\
\hline & & $\mathrm{N}=152$ \\
\hline
\end{tabular}

** In the 0/99 was significant.

As results displayed in Table1 there was a significant relationship between ICT and knowledge management in Sari municipality staff, because the observed significance level(Sig=0.000) is lower than the value of the predicted error $(0.01)$. Therefore, with $99 \%$ level of confidence the $\mathrm{H}_{0}$ hypothesis was rejected and $\mathrm{H}_{1}$ hypothesis was confirmed. On the other hand, taking into account the coefficient of determination $\left(\mathrm{R}^{2}\right)$, can be said 0.26 of 


\section{Macrothink}

Journal of Management Research

ISSN 1941-899X

2017, Vol. 9, No. 4

changes in knowledge management depends on the change of a single information and communication technology, and the rest depends on other factors.

- The second hypothesis: There is a significant relation between ICT and its components and component of knowledge management.

$\mathrm{H}_{0}: \mathbf{r}=\mathbf{0}$

$\mathrm{H}_{1}: \mathbf{r} \neq \mathbf{0}$

It is noted that in response to the second hypothesis, according to Table2, ICT and components there of (including Automation, Processing, Storage, Informing and Communication) with the components of knowledge management (including Socialization, Internalization, Externalization and a Combination) were studied and analyzed.

Table 2. Relationship between ICT and its components and elements of KM

\begin{tabular}{|c|c|c|c|c|c|c|}
\hline \multicolumn{2}{|c|}{ Criterion } & \multirow{2}{*}{$\begin{array}{l}\text { Indice } \\
\qquad \mathrm{s}\end{array}$} & \multicolumn{4}{|c|}{ KM } \\
\hline \multicolumn{2}{|r|}{ Predictive } & & $\begin{array}{c}\text { Socializatio } \\
\mathrm{n}\end{array}$ & $\begin{array}{c}\text { Internalizatio } \\
\mathrm{n}\end{array}$ & $\begin{array}{c}\text { Externalizatio } \\
\mathrm{n}\end{array}$ & $\begin{array}{c}\text { Combinatio } \\
\mathrm{n}\end{array}$ \\
\hline \multirow{3}{*}{\multicolumn{2}{|c|}{ ICT }} & $r$ & $0.41^{* *}$ & $0.47^{* *}$ & $0.43^{* *}$ & $0.50^{* *}$ \\
\hline & & $\mathrm{R}^{2}$ & $0 / 17$ & 0.22 & 0.18 & 0.24 \\
\hline & & Sig & 0.000 & 0.000 & 0.000 & 0.000 \\
\hline \multirow{15}{*}{ 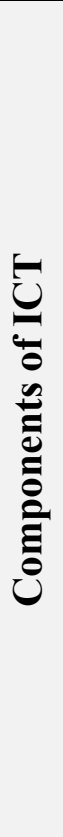 } & \multirow{3}{*}{ Automation } & $\mathrm{r}$ & $0.25^{* *}$ & $0.28^{* *}$ & $0.25^{* *}$ & $0.33^{* *}$ \\
\hline & & $\mathrm{R}^{2}$ & 0.06 & 0.07 & 0.06 & 0.11 \\
\hline & & Sig & $0 / 002$ & 0.001 & 0.002 & 0.000 \\
\hline & \multirow{3}{*}{ Processing } & $\mathrm{r}$ & $0.32^{* *}$ & $0.50^{* *}$ & $0.33^{* *}$ & $0.43^{* *}$ \\
\hline & & $\mathrm{R}^{2}$ & 0.10 & 0.24 & 0.11 & 0.18 \\
\hline & & Sig & 0.000 & 0.000 & 0.000 & 0.000 \\
\hline & \multirow{3}{*}{ Storage } & $\mathrm{r}$ & $0.46^{* *}$ & $0.36^{* *}$ & $0.36^{* *}$ & $0.39^{* *}$ \\
\hline & & $\mathrm{R}^{2}$ & 0.21 & 0.13 & 0.13 & 0.15 \\
\hline & & Sig & 0.000 & 0.000 & 0.000 & 0.000 \\
\hline & \multirow{3}{*}{ Informing } & $\mathrm{r}$ & $0.40^{* *}$ & $0.45^{* *}$ & $0.43^{* *}$ & $0.47^{* *}$ \\
\hline & & $\mathrm{R}^{2}$ & 0.16 & 0.21 & 0.19 & 0.22 \\
\hline & & Sig & 0.000 & 0.000 & 0.000 & 0.000 \\
\hline & \multirow{3}{*}{$\begin{array}{c}\text { communicatio } \\
\mathrm{n}\end{array}$} & $\mathrm{r}$ & $0.33^{* *}$ & $0.39^{* *}$ & $0.48^{* *}$ & $0.49^{* *}$ \\
\hline & & $\mathrm{R}^{2}$ & 0.11 & 0.15 & 0.23 & 0.24 \\
\hline & & Sig & 0.000 & 0.000 & 0.000 & 0.000 \\
\hline
\end{tabular}

** In the $0 / 99$ was significant.

The findings of the correlation between ICT and its component and knowledge management showed: 
1. There was a significant relation between ICT and socialization. There was a significant relation between all components of ICT and socialization. And socialization was most affected by the storage.

2. There was a significant relation between ICT and internalization. There was a significant relation between all components of ICT and internalization. And internalization was most affected by the processing.

3. There was a significant relation between ICT and Externalization. There was a significant relation between all components of ICT and Externalization. And Externalization was most affected by the communication.

4. There was a significant relation between ICT and Combination. There was a significant relation between all components of ICT and Combination. And Combination was most affected by the communication.

- The third hypothesis. There is a significant difference between ICT and knowledge management separately between men and women.

$\mathrm{H}_{0}: \boldsymbol{\rho}_{1}=\boldsymbol{\rho}_{2}$

$\mathrm{H}_{1}: \boldsymbol{\rho}_{1} \neq \boldsymbol{\rho}_{2}$

Table 3. Comparison of relation between ICT and KM of male and female employees

\begin{tabular}{|c|c|c|c|c|}
\hline Criterion variable & $\begin{array}{c}\text { Female } \\
\text { KM }\end{array}$ & $\begin{array}{c}\text { Male } \\
\text { KM }\end{array}$ & $\begin{array}{c}\text { Obtained Z } \\
\text { value }\end{array}$ & $\begin{array}{c}\text { Critical Z } \\
\text { value }\end{array}$ \\
\hline Predictive variable & $0.48^{* *}$ & $0.52^{* *}$ & 0.25 & 1.96 \\
\hline ICT & &
\end{tabular}

** In the 0/99 was significant.

As results displayed in Table3, there was not a significant statistical difference between ICT and knowledge management separately between men and women with the error level of $\alpha$ $=0.05$. Since the obtained $\mathrm{Z}$ value is less than critical $\mathrm{Z}$ value, $\mathrm{H}_{0}$ was accepted and $\mathrm{H}_{1}$ was rejected.

As well as regarding the relationship between ICT and knowledge management, Fit model was performed by using LISREL software. The results are listed below: 


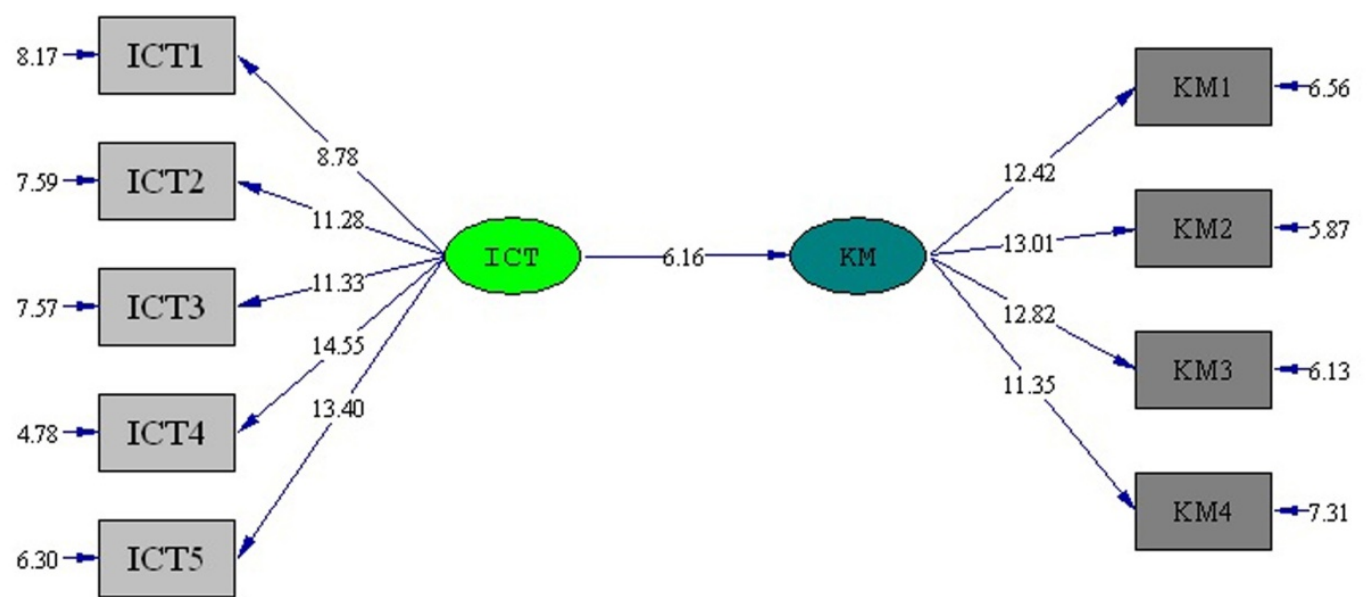

Chi-Square=118.64, $\mathrm{df}=26, \mathrm{P}$-value=0.00000, RMSEA $=0.154$

Figure 2. T-test model analysis

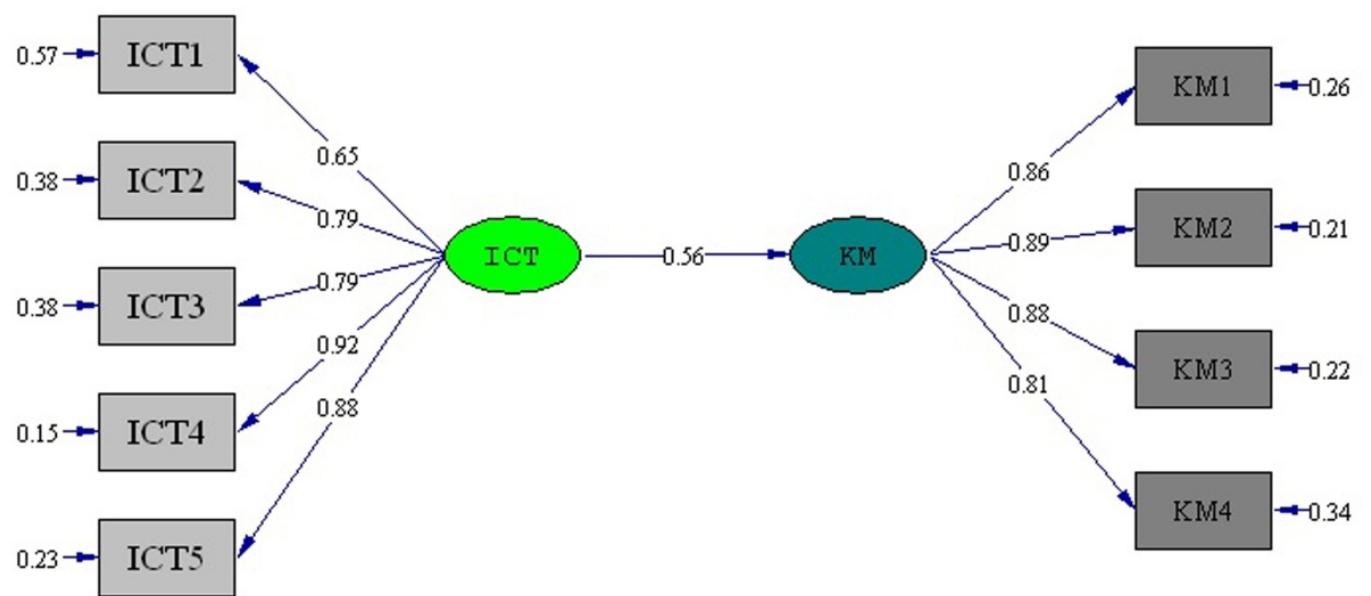

Chi-Square=118.64, $\mathrm{df}=26, \mathrm{P}$-value=0.00000, RMSEA $=0.154$

Figure 3. Standardized coefficients path analysis 


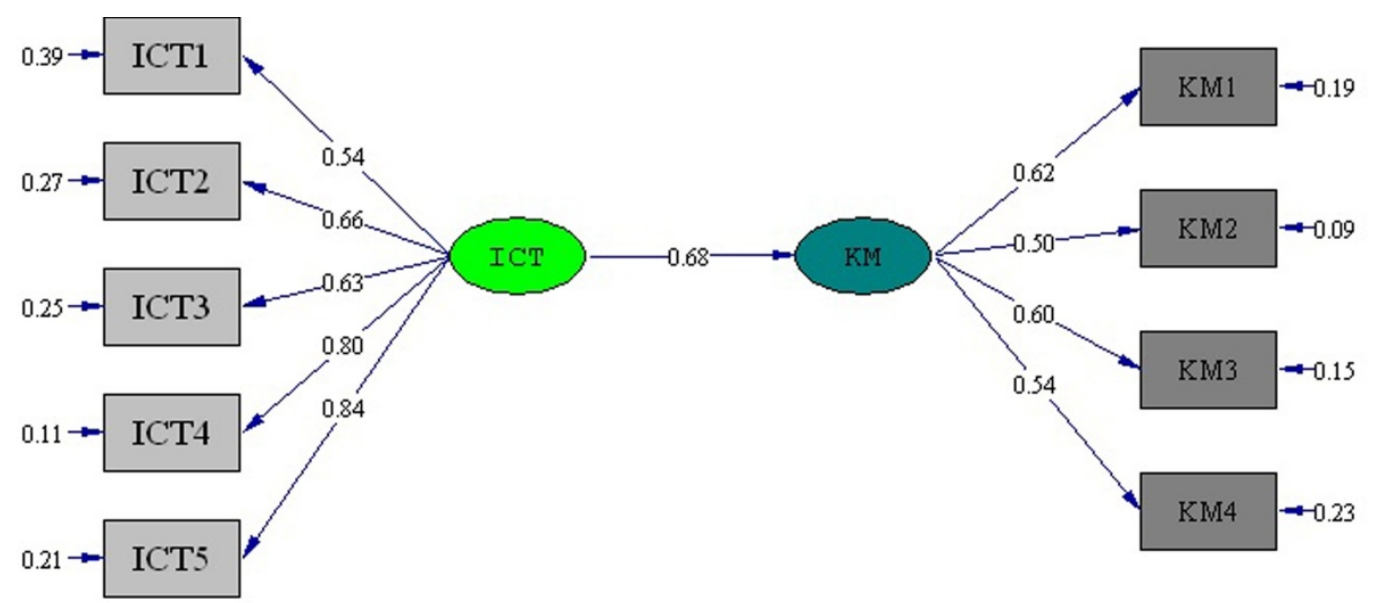

Chi-Square $=118.64, \mathrm{df}=26, \mathrm{P}$-value $=0.00000, \mathrm{RMSEA}=0.154$

Figure 4. Non- standardized coefficients path analysis

Table 4. Estimating indices model

\begin{tabular}{|l|c|}
\hline \multicolumn{1}{|c|}{ Fit Index } & Estimated value \\
\hline Chi-Square & 118.84 \\
\hline Degrees of Freedom (DF) & 26 \\
\hline Chi-Square/ Degrees of Freedom & 4.57 \\
\hline Root Mean Square Error of Approximation (RMSEA) & 0.154 \\
\hline Root Mean Square Residual (RMR) & 0.030 \\
\hline Standardized Root Mean Square Residual (SRMR) & 0.044 \\
\hline Normed Fit Index (NFI) & 0.92 \\
\hline Non-Normed Fit Index (NNFI) & 0.90 \\
\hline Comparative Fit Index (CFI) & 0.93 \\
\hline Goodness of Fit Index (GFI) & 0.85 \\
\hline Adjusted Goodness of Fit Index (AGFI) & 0.74 \\
\hline
\end{tabular}

Table4 showed that the value of chi-square $\left(\chi^{2}\right)$ was 118.84 and degrees of freedom were 26 , so the ratio estimation of the chi-square to degree of freedom was 4.57. The smaller this value is, closer to 1 , the model is more appropriate (Preferably it should be below 3). The calculated Root Mean Square Error of Approximation (RMSEA) was 0.154 which was in the range of $0.1<\mathrm{X}<0.5$ and represented the moderate status. The Root Mean Square Residual (RMR) was 0.03 that was less than 0.05 , which represented a good status. The Comparative Fit Index was above 0.9, which indicated a good condition. The Normed Fit Index (NFI) was 0.92, and the Goodness of Fit Index (GFI) was 0.85 and the Adjusted Goodness of Fit Index (AGFI) was 0.74. Overall, despite conforming specified model, the proposed model was an appropriate model. 
This hypothesis (i.e. there is a relationship between ICT research and knowledge management), was accepted with the error level of 0.05 , because the t-values of each of the coefficients of the measurement and structural equation were greater than 1.96.

\section{Conclusion}

The results of the study indicated that there was a significant relation between ICT and knowledge management. There was a significant relation between ICT and its components and component of knowledge management. These findings are in line with Damghanian \& et al.(2013), Sobhani \& et al.(2013), Meyer \& Marion(2013), Yang \& et al.(2012), Kheirandish $\&$ et al.(2011), Tseng(2008). It was also found that although there was no significant statistical difference between ICT and knowledge management between men and women, men had a higher level of knowledge management than women. This finding is in line with Damghanian \& et al.(2011), Gurteen (2010), Yaqoubi \& et al.(2010), Morrison(2007), Yousefi \& et al.(2006), Ramsey \& McCorduck (2005), Ahuja(2002).

Finally, model of the relationship between ICT and knowledge management was tested, and was considered appropriate based on Goodness of Fit indices.

The results showed that ICT systems are considered as an effective aid in reducing the loss of knowledge. In fact, ICT can be effective to improve knowledge management. The findings also showed that knowledge management practice approved the mediation effect of IT on the performance of the project in terms of program success, cost savings as well as quality and safety performance. ICT can provide mechanisms that can be used for tangible assets of knowledge, transfer knowledge and improve job performance.

On the other hand, ICT as a moderating factor increase participation of employees as well as employee satisfaction in activities, and thus is influential on effectiveness and efficiency of all activities of the organization. On the other hand, Technology users in a higher level are in a better position in terms of empowerment index, and ICT because of its special nature that it does not matter the sex and age limitations, can have an important role in increasing empowerment. However, while the expectations of the capabilities of information and communications technology are high, it should be stressed that such technologies are not able to respond to all the problems of staff, but may only open opportunities, resources and modern information and communication channels for empowerment, self-reliance and development in human societies.

Accordingly, taking into account the overall result obtained from this study and similar studies can be said that men are more better than women in knowledge management cycle by having equal opportunities in ICT; Men are more successful in the transmission and acquisition of knowledge as well as changing their inner knowledge to explicit knowledge, men act their job duties with a different view. Informal communication among men in the organization would lead to increase job satisfaction. On the other hand friendly relation is a way to establish and transfer knowledge. According to Damghanian \& et al. (2011), considering relationships, creating a favorable environment for friendly relations, providing opportunity to chat and debate about work, making informal relationships while doing work 
can help the knowledge management cycle. Men acted more successful in creating these conditions, their inner knowledge (which is the tacit knowledge and implicit) transferred during informal relationships to their colleagues and in the same condition they received overt and covert knowledge from them. In fact, it can be said the activities of men and their feature help to facilitate knowledge management cycle.

According to the results of this study, solutions can be suggested to improve the relationship between ICT and knowledge management as well as strengthen knowledge management cycle:

- As a result of multiple investigations and research showed there was a significant relationship between ICT and knowledge management. So in order to more efficient use of ICT for knowledge management is proposed: 1.Help to the implementation of knowledge management, by selecting appropriate information and communication technologies and updating them; 2. In addition to promoting investment in technology infrastructure, organization addressed the use of their knowledge; 3 . Despite the best and most suitable technological tools without the ability of employees to use them, there would be no benefit to the organization. Accordingly, we can provide the necessary training to recognize technological tools and the way to use them and also ICDL training to improve knowledge management.

- As the results showed, although there was not a significant difference in terms of information and communication technology and knowledge management between women and men, and this association was measured stronger among men than women. So in order to strengthen the knowledge management cycle can help to increase the success of knowledge management for men with more investment in the appropriate databases, training men, holding international conferences, active participation of male employees in decision-making, more importance to the creative ideas of the men, periods such as teamwork, internet, intranet and other technologies. However, these activities will be effective in both groups, but it has been observed in this organization that men were better and faster.

In short, in current era information and communication are considered as infrastructure development, therefore, organizations must move towards the development to be able to survive in today's world. Every movement and any changes require planning and infrastructure. The organization contributed to the successful implementation of the project, with an investment, update and strengthen the infrastructure of information and appropriate communication technologies to knowledge management projects.

\section{References}

Adli, Fariba. (2005). Knowledge Management, Moving Beyond the Knowledge. Tehran: Andishe. 
Ahmadi Baladehi, Mehdi, \& Mirzaee Arabi, Mohammad Ali. (2014). Establishment of Knowledge Management and Its Relationship with NAJA Staff Creativity. NAJA Human Resources, 9(37), 29-48.

Ahuja, Manju K.(2002).Women in Information Technology Profession: A Literature Review , Synthesis and Research Agenda. European Journal of Information Systems, 11(1), 20-34. https://doi.org/10.1057/palgrave.ejis.3000417

Azadi Ahmadabadi, Qasem, \& Azadi Ahmadabadi, Akram. (2009). Information Technology in Knowledge Management; Applications and Effects. Tadbir, 20(211), 55-60. http://www.ensani.ir/fa/content/164703/default.aspx

Bergeron, Bryan. (2007). Essentials Knowledge Management(Translated by Manouchehr Ansari). Tehran: Ketab nashr mehraban.

Bloodgood, James M., \& Salisbury, Wm. David. (2001). Understanding the influence of Organizational change Strategies on information technology and knowledge management $\begin{array}{llll}\text { Strategies. } & \text { Decision } & \text { Support } & \text { Systems, }\end{array}$ https://doi.org/10.1016/S0167-9236(00)00119-6

Damghanian, Hossein; Zarei, Azim, \& Roozban, Farnaz.(2011).Comparison of Knowledge Management and Information Technology Between Men and Women. Women and Culture, 2(8), 61-71.

Damghanian, Hossein; Zarei, Azim \& Roozban, Farnaz.(2013).The Effect of Information Technology on Knowledge Management Mediated by Empowering the National Iranian

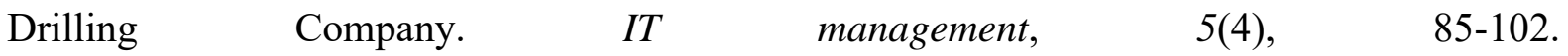
http://fa.journals.sid.ir/ViewPaper.aspx?id=225964

Kheirandish, Mehdi; Doostkam, Kazem, \& Hosseiniaei, Yahya. (2012). Role of Technological Factors in the Success of Knowledge Management in the Organization. Military management, 11(44), 69-88.

Lee, Heeseok, \& choi, Byounggu.(2003).Knowledge Management enablers, Process and Organizational Performance: An Integrative View and Empirical Examination. Journal of $\begin{array}{llll}\text { Management Information } & \text { Systems, } & \text { 20(1), }\end{array}$ http://dx.doi.org/10.1080/07421222.2003.11045756

Mahdavi, Mohammadtaghi. (2010). Information Technology and Technology's Information. Tehran: Chapar.

Meyer, Marc H., \& Marion, Tucker J. (2013). Preserving the integrity of knowledge and information in R\&D. Business Horizons, 56(1), 51-61. https://doi.org/10.1016/j.bushor.2012.09.003

Neels, C.J., \& Johnson, Roy. D. (2010). Information management as an enabler of knowledge management maturity: a south African perspective. International journal of information management, 30, 57-67. 
Rajabi, Ali Mohammad, \& Shah Mohammadi, Qolamreza. (2013). A Model for the Application of Information Technology in Knowledge Management Iran NAJA. Management Studies on Police Training, 6(1), 104-139.

Rampai, Nattaphon, \& Sompong, Narong. (2015). The development model of knowledge management to strengthen Thai ict community learning center. Procedia - Social and Behavioral Sciences, 176, 139 - 147. https://doi.org/10.1016/j.sbspro.2015.01.454

Ramsey, Nancy, \& McCorduck, Pamela. (2005). Where are the women in Information Technology, National center for women \& technology, university of Colorado.

Robbins, Stephen. (2008). Principles of Organizational Behavior(translated by Ali Parsaeian \& S. Mohammad Arabi). Tehran: Office of Cultural Research. (Original Work Published 1996).

Secretariat, L.(2005). Information Communication and Space Technology for Meeting Development Challenges. Economic and Social Commission for Asia and the Pacific, Special Body on Least Developed and Landlocked Developing Countries. United Nations Conference on Trade and Development, 83.

Sobhani, Yazdan; Honari, Habib; Shahlaei, Javad, \& Ahmadi, Alireza.(2013).The Relationship between Information Technology and Knowledge Management in Sport Federations. Sport Management, 5(17), 55-73.

Teresa, Maria \& Alvarez, Garcia. (2015). Analysis of the effects of ICTs in knowledge management and innovation: The case of Zara Group. Computers in Human Behavior, 51, 994-1002. https://doi.org/10.1016/j.chb.2014.10.007

Teseng, Shu-Mei. (2008). The effects of information technology on knowledge management systems. Expert Systems with Applications, 35(1-2), 150-160. http://doi.org/10.1016/j.eswa.2007.06.011

Wang, Catherine L., \& Ahmed, Pervaiz K. (2003). Structural dimensions for knowledge based Organizations. Measuring Business Excellence, 7(1), 51-62. https://doi.org/10.1108/13683040310466726

Yang, Li-Ren; Chen, Jieh-Haur, \& Wang, Hsiao-Wen. (2012). Assessing impacts of information technology on project success through knowledge management practice. Automation in Construction, 22, 182-191. https://doi.org/10.1016/j.autcon.2011.06.016

Yaqubi, Maryam; Javadi, Marzieh, \& Aqarahimi, Zahra. (2010). The Relationship Between Knowledge Management and Demographic Characteristics of Students' of Isfahan University of Medical Sciences. Special Edition of Educational Development, 10(5), 831-838. 